\title{
Contraceptive efficacy of sperm agglutinating factor from Staphylococcus warneri, isolated from the cervix of a woman with inexplicable infertility
}

Neeraj Chandra Pant ${ }^{1}$, Ravinder Singh', Vijaya Gupta', Aditi Chauhan', Ravimohan Mavuduru², Vijay Prabha ${ }^{1}$ and Prince Sharma ${ }^{1 *}$

\begin{abstract}
Background: Voluntary control of fertility is of paramount importance to the modern society. But since the contraceptive methods available for women have their limitations such as urinary tract infections, allergies, cervical erosion and discomfort, a desperate need exists to develop safe methods. Vaginal contraceptives may be the answer to this problem, as these are the oldest ways of fertility regulation, practiced over the centuries. With minimal systemic involvement, these are also the safest. Natural substances blocking or impairing the sperm motility offer as valuable non-cytotoxic vaginal contraceptives. Antimicrobial peptides (AMPs) isolated from plants, animals and microorganisms are known to possess sperm immobilizing and spermicidal properties. Following this, in the quest for alternative means, we have cloned, over expressed and purified the recombinant sperm agglutinating factor (SAF) from Staphylococcus warneri, isolated from the cervix of a woman with unexplained infertility.
\end{abstract}

Methods: Genomic library of Staphylococcus warneri was generated in Escherichia coli using pSMART vector and screened for sperm agglutinating factor (SAF). The insert in sperm agglutinating transformant was sequenced and was found to express ribonucleotide-diphosphate reductase-a sub unit. The ORF was sub-cloned in pET28a vector, expressed and purified. The effect of rSAF on motility, viability, morphology, $\mathrm{Mg}^{++}$-dependent ATPase activity and acrosome status of human sperms was analyzed in vitro and contraceptive efficacy was evaluated in vivo in female BALB/C mice.

Results: The $80 \mathrm{kDa}$ rSAF showed complete sperm agglutination, inhibited its $\mathrm{Mg}^{2+}$-ATPase activity, caused premature sperm acrosomal loss in vitro and mimicked the pattern in vivo showing $100 \%$ contraception in BALB/C mice resulting in prevention of pregnancy. The FITC labeled SAF was found to bind the entire surface of spermatozoa. Vaginal application and oral administration of rSAF to mice for 14 successive days did not demonstrate any significant change in vaginal cell morphology, organ weight and tissue histology of reproductive and non-reproductive organs and had no negative impact in the dermal and penile irritation tests.

Conclusion: The Sperm Agglutinating Factor from Staphylococcus warneri, natural microflora of human cervix, showed extensive potential to be employed as a safe vaginal contraceptive.

Keywords: Staphylococcus warneri, Sperm agglutinating factor, FITC, $\mathrm{Mg}^{2+}$-ATPase, Acrosome reaction, Contraceptive efficacy, Safety study

\footnotetext{
* Correspondence: princess@pu.ac.in

'Department of Microbiology, South Campus, Basic Medical Science (Block I),

Panjab University, Sector 25, Chandigarh 160014, India

Full list of author information is available at the end of the article
}

(c) The Author(s). 2019 Open Access This article is distributed under the terms of the Creative Commons Attribution 4.0 International License (http://creativecommons.org/licenses/by/4.0/), which permits unrestricted use, distribution, and

reproduction in any medium, provided you give appropriate credit to the original author(s) and the source, provide a link to the Creative Commons license, and indicate if changes were made. The Creative Commons Public Domain Dedication waiver (http://creativecommons.org/publicdomain/zero/1.0/) applies to the data made available in this article, unless otherwise stated. 


\section{Background}

The burgeoning population is a serious concern and contraception is considered the most accepted way of controlling it [1]. Female contraceptive methods include intrauterine devices (IUDs), barriers, sterilization, hormone-based treatment (oral/injectable) and insert contraceptives. Out of these, the most well-known are hormone-based contraceptives. Despite the fact that these have great contraceptive efficacy and reversibility, they have many side effects viz. spotting and irregular bleeding, weight increase, queasiness, and mood alterations; are irritating and exceptionally troubling sometimes, which lead to their discontinuation [2]. To some degree, distinctive yet similar issues lead to considerably less use of IUDs as they may lead to infection, heavy menstrual bleeding, dysmenorrhea, and pain during insertion [3]. Likewise, barrier methods of contraception are though effective but also suffer from certain side effects such as difficulty in insertion, allergic reactions to latex or polyurethane, vaginal irritation, cervical erosion, urinary tract infections and rarely toxic shock syndrome, if the device is left set up for a really long time [4]. Sterilization is an excellent choice for women who truly want to terminate childbearing, but being an irreversible method, there is evidence of some regret, particularly among women sterilized at younger ages [5]. Every contraceptive method in use today has shortcomings, and collectively they leave major voids in the ability of people to control fertility safely, effectively, and in culturally acceptable ways throughout their reproductive life. Therefore, there is need to provide woman with safe and effective alternatives.

Commercially available vaginal contraceptive formulations contain non-ionic surfactants such as nonoxynol-9 (N-9), as an active ingredient that causes irreversible immobilization of human spermatozoa but affects vaginal microflora and the epithelial cells when used frequently [6]. Non-invasive contraceptive agents with spermicidal activity are acrylophenones, vanadocenes, gel microemulsions (GM-4, GM-44), sylidines, thymols, and isoxazoles/isoxazolines [7]. Amongst the natural products, saponins isolated from the fruit pericarp of Sapindus mukorossi [8], magainin-A from the skin of the African clawed frog Xenopus laevis $[9,10]$ nisin- a bacteriocin produced by Lactococcus lactis [11-13] and subtilosin from Bacillus subtilis and B. amyloliquefaciens possess good spermicidal activity [14].

Recombinant proteins such as heat labile enterotoxin subunit B genetically linked with hCG- $\beta$ chain [15], recombinant bonnet monkey zona pellucida (ZP1) conj $\mu-$ gated to diphtheria toxoid (used to immunize female baboons) [16] and sperm specific antigen, NZ1, have been reported to prevent pregnancy [17]. Also, various microorganisms reported to immobilize or agglutinate spermatozoa are Escherichia coli [18], Chlamydia trachomatis [19], Mycoplasma genitalium [20], Ureaplasma urealyticum [21], Staphylococcus aureus [22] and Candida albicans [23]. Hence, bacterial proteins can be explored and developed as contraceptive agents.

In this work, Staphylococcus warneri (S. warneri), isolated previously in our laboratory from the cervix of a woman with inexplicable infertility, was found to agglutinate human and mouse spermatozoa in vitro. Further, sperm agglutinating factor (SAF) was isolated and purified and was able to show complete sperm agglutination in vitro. However, as the gene responsible for sperm agglutinating activity was unknown and the production of SAF from wild type bacteria was very low, the present study was designed to identify the SAF and enhance its production by heterologous over expression and to further evaluate the efficacy of recombinant SAF as a contraceptive agent in a female mouse model.

\section{Methods \\ Bacterial strains and plasmid}

S. warneri isolated from the cervix of a woman with inexplicable infertility, showed sperm agglutinating activity and was identified by Matrix-assisted laser desorption/ ionization (MALDI) Microflex LT mass spectrometer [24]. It was maintained in Brain Heart Infusion broth. Plasmid pSMART, expression vector pET28a and Escherichia coli (E. coli) DH10ß and BL21 (DE3) strains were used for the cloning and expression of recombinant protein.

\section{Sperm-bacteria interaction for sperm agglutinating activity}

Sperm agglutinating activity was carried out as described earlier by Pant et al. [24]. Breifly, S. warneri was grown in Luria Broth (LB) at $37^{\circ} \mathrm{C} / 180 \mathrm{rpm}$ for $72 \mathrm{~h}$, following which it was centrifuged at $10,000 \mathrm{xg}$ for $10 \mathrm{~min}$ at $4{ }^{\circ} \mathrm{C}$. The supernatant was passed through a $0.22 \mu \mathrm{m}$ Millipore filter to ensure that it was cell free. The bacterial cells so obtained were washed twice with sterile PBS. Equal volumes of semen sample $\left(40 \times 10^{6}\right.$ spermatozoa $\left.\mathrm{ml}^{-1}\right)$, whole cell culture or washed cells $\left(10^{7}\right.$ cells $\left.\mathrm{ml}^{-1}\right)$ or cell free supernatant were mixed and incubated at $37^{\circ} \mathrm{C}$ for $0,15,30,60,120$ and $240 \mathrm{~min}$ and observed for agglutination at 400X magnification under light microscope. Sterile LB was used as control.

\section{Construction of genomic library}

Chromosomal DNA was isolated and was partially restricted with HaeIII. The digest was run on a preparative gel and the agarose gel containing fragments $(2-6 \mathrm{~kb})$ was excised by sterile blade to extract DNA using the commercial QIAquick Gel Extraction kit (QIAGEN). Ligation was carried out with the linear PSMART vector 
(Lucigen) and transformed in electrocompetent E. coli DH10 $\beta$ cells (Lucigen) [24].

\section{Purification of recombinant sperm agglutinating factor (rSAF)}

The recombinant cells were grown in LB-kanamycin for $72 \mathrm{~h}$, washed twice with phosphate buffer saline (PBS) $\mathrm{pH} 7.4$, sonicated and centrifuged at $10,000 \mathrm{xg}$ for 20 min at $4{ }^{\circ} \mathrm{C}$. Both the supernatant and pellet were checked for sperm agglutinating activity. Further, fractionation of supernatant was done with ammonium sulphate to get $20,40,60,80$ and $100 \%$ saturation and the precipitated and dialysed fractions were checked for activity. The bioactive fractions were further purified by Sephadex G-200 and checked for sperm agglutinating activity.

\section{Cloning, over-expression and purification of recombinant SAF}

Chromosomal DNA of S. warneri was isolated [25] and used as template for PCR. Primers were designed by online tool 'OligoEvaluator ${ }^{\text {rs }}$ ' having EcoRI and HindIII restriction sites in forward (5'-AATGAATTCAATTGC ACAACTTGTAC-3') and reverse primer (5'-CGCAAGCTTATGAAAACTATGGACGAG-3), respectively. PCR reaction was performed with initial denaturation at $94{ }^{\circ} \mathrm{C}$ for 3 min followed by 33 thermal cycles of denaturation at $95^{\circ} \mathrm{C}$ for $1 \mathrm{~min}$, annealing at $55^{\circ} \mathrm{C}$ for $45 \mathrm{~s}$, extension at $72{ }^{\circ} \mathrm{C}$ for $2 \mathrm{~min}$ and final extension at $72{ }^{\circ} \mathrm{C}$ for $10 \mathrm{~min}$. The EcoRI and HindIII digested PCR product was ligated to similarly digested pET-28a and transformed into E. coli BL21 (DE3) by electroporation. Transformants were selected on LB-kanamycin agar plates and confirmed by polymerase chain reaction (PCR) [26]. For overexpression and purification, $500 \mathrm{ml}$ of LB-kanamycin was inoculated with $2.5 \mathrm{ml}$ of overnight grown inoculum of $E$. coli BL21 (DE3) containing pET-28a-SAF. When $\mathrm{OD}_{600}$ reached 0.8 , Isopropyl $\beta$-D-1-thiogalactoside (IPTG) $(0.5 \mathrm{mM})$ was added and incubated for $5 \mathrm{~h}$ at $37^{\circ} \mathrm{C} / 150 \mathrm{rpm}$. The cells were pelleted and suspended in $50 \mathrm{ml}$ buffer $(100 \mathrm{mM}$ phosphate buffer, $300 \mathrm{mM} \mathrm{NaCl}$, $\mathrm{pH}$ 8) containing $1 \mathrm{mg} / \mathrm{ml}$ lysozyme. The cell suspension was sonicated, centrifuged and loaded on Ni-NTA column. The column was washed with five column volumes of wash buffer (20 mM Tris- $\mathrm{HCl}, 500 \mathrm{mM} \mathrm{NaCl}$, $20 \mathrm{mM}$ imidazole, $\mathrm{pH} 8.0$ ) to remove non-specific proteins. The bound SAF was eluted with buffer containing $20 \mathrm{mM}$ Tris- $\mathrm{HCl}, 500 \mathrm{mM} \mathrm{NaCl}, 100 \mathrm{mM}$ phosphate buffer, $250 \mathrm{mM}$ imidazole, $\mathrm{pH}$ 8.0. Eluted fractions were collected and analyzed by $12 \%$ SDS PAGE [27]. Imidazole was removed by dialysis against PBS and protein concentration was estimated by Bradford kit and checked for sperm agglutinating activity.

\section{Binding of rSAF with spermatozoa}

For this, $2 \mathrm{mg}$ of purified protein was mixed with Fluorescence isothiocyanate (FITC), according to F/P ratio as per the instructions given in the kit (GeNei FITC Labelling Kit procured from Banglore Genei (India) Pvt. Ltd.). $100 \mu \mathrm{l}$ of washed sperm suspension was incubated with $200 \mu \mathrm{l}$ of FITC-rSAF at $37^{\circ} \mathrm{C}$ for $1 \mathrm{~h}$, post which $150 \mu \mathrm{l}$ of $3 \%$ formaldehyde was added and again incubated at $37^{\circ} \mathrm{C}$ for $1 \mathrm{~h}$. After the completion of incubation period, the reaction mixture was washed thrice and suspended in $50 \mu \mathrm{l}$ of PBS. A wet mount was prepared and observed under fluorescent microscope (1000X magnification).

\section{In vitro effect of rSAF on sperm morphology}

Scanning electron microscopy (Joel Scanning Microscope, 6100, Jeol, Japan) was done to study the effect of rSAF on human spermatozoa morphology. Processing of samples was done according to the method described by [28].

\section{In vitro effect of rSAF on $\mathrm{Mg}^{2+}$-ATPase activity of spermatozoa}

$\mathrm{Mg}^{2}{ }^{+-}$ATPase activity of spermatozoa was estimated according to the protocol of [29] and [30]. Briefly, Tris$\mathrm{HCl}(0.2 \mathrm{M}, \mathrm{pH} 7.6)$ washed spermatozoa $\left(1 \times 10^{8} / \mathrm{mL}\right)$ were sonicated at $50 \mathrm{~Hz}(10$ cycles of $30 \mathrm{~s}$ with $1 \mathrm{~min}$ interval) at $4{ }^{\circ} \mathrm{C}$. The reaction mixture for ATPase consisted of $200 \mu \mathrm{l}$ each of Tris- $\mathrm{HCl}$ buffer (0.2 M, pH 7.6), $\mathrm{Mg} \mathrm{Cl}_{2}$ (5 mM), ATP (6 mg mL-1), and sonicated sperm suspension. Different concentrations of $\operatorname{rSAF}(12.5,25$, 50 and $100 \mu \mathrm{g}$ ) were separately added and incubated at $37^{\circ} \mathrm{C}$ for $1 \mathrm{~h}$, post which the reaction was halted by adding $1 \mathrm{~mL}$ of cold $10 \%$ Tricholoroacetic acid (TCA) and then incubated at $4{ }^{\circ} \mathrm{C}$ overnight for protein precipitation. The control tubes contained all the components of the reaction mixture except that TCA was added in the beginning to halt the ATPase activity. Inorganic phosphorus $(\mathrm{Pi})$ released was determined according to the method of [31]. One unit of ATPase was expressed as $\mu$ moles of the Pi released after $1 \mathrm{~h}$ of incubation.

\section{In vitro effect of rSAF on acrosome reaction of spermatozoa}

The washed semen samples were resuspended in Ham's F-10 medium (containing HEPES and 1\% human serum albumin) were incubated for $3 \mathrm{~h}$ at $37^{\circ} \mathrm{C}$, post which spermatozoa were collected by centrifugation $(500 \times \mathrm{g}$ for $10 \mathrm{~min}$ ) and their motility was assessed. The aliquots of motile spermatozoa $\left(20 \times 10^{6}\right.$ cells $)$ incubated with either 0.1\% Dimethyl sulfoxide (DMSO) (negative control) or $10 \mu \mathrm{M}$ Calcium ionophore A23187 (positive control) or $25 \mu \mathrm{g}$ of $\mathrm{rSAF}$ and incubated for $1 \mathrm{~h}$ at $37^{\circ} \mathrm{C}$. For the assessment of acrosomal status, a smear of sperm pellet was prepared on a glass slide, fixed with $95 \%$ ethanol for 
$30 \mathrm{~min}$, air dried, washed with distilled water for $10 \mathrm{~min}$ and stained for $4 \mathrm{~h}$ with $25 \mathrm{mg} / \mathrm{mL}$ Pisum sativum agglutinin-Fluorescein isothiocyanate (PSA-FITC) in PBS (pH 7.4) at $4{ }^{\circ} \mathrm{C}$. The slides were washed with distilled water, air dried and covered with $30 \mu \mathrm{L}$ of anti-fading medium (50\% v/v glycerol, $50 \% \mathrm{v} / \mathrm{v}$ distilled water, $25 \mathrm{mg} /$ $\mathrm{mL} \mathrm{1',4-diazabicyclo} \mathrm{[2]} \mathrm{octane)} \mathrm{and} \mathrm{at} \mathrm{least} 100$ spermatozoa were examined using a fluorescence microscope at 1000X. When more than half the head of a spermatozoon fluoresced brightly and uniformly, the acrosome was considered intact. Spermatozoa without fluorescence or with a fluorescing band limited to the equatorial segment were considered acrosome-reacted.

\section{In vivo contraceptive efficacy of rSAF Animals}

Sexually mature and randomly bred (5-6 week old male and 4-5 week old female) BALB/c mice were used. The animals were housed in polypropylene cages and were maintained under laboratory conditions (12:12, dark: light cycle) and fed with standard pellet diet and water ad libitum. All the animal procedures were designed for minimum pain and discomfort. The experimental protocols were approved by the Institutional Animal Ethics Committee of the Panjab University, Chandigarh, India vide letter no. PU/IAEC/S/15/72 and were performed in accordance with the guidelines of the Committee for the Purpose of Control and Supervision of Experiments on Animals (CPCSEA).

\section{Fertility outcome}

For the examination of contraceptive efficacy of rSAF, female BALB/c mice were used. In control group $(n=3)$, mice were administered with single intravaginal dose of $20 \mu \mathrm{l}$ PBS. The test group was divided into 3 sub-groups with 5 mice in each sub-group receiving different concentrations of $\operatorname{rSAF}(2.5,5$ and $10 \mu \mathrm{g})$. Mice used for fertility studies were synchronised in their oestrous cycles by Whitten effect [32]. rSAF was deposited in the vagina while the mice were held in supine position for 1 min. All the animals were allowed to mate overnight with males of proven fertility (2:1). Next morning, the females were monitored for the presence of vaginal plug as confirmation of mating and the males were separated. The mice were examined for weight gain, abdominal distension and palpation of string of pearls and were kept under observation for entire gestation period.

\section{Histological studies}

From the above mentioned groups, one mouse each from control and test group were sacrificed on day 14 for histological evaluation. Reproductive organs were harvested, fixed in $10 \%$ formaldehyde for $24 \mathrm{~h}$ and then embedded in paraffin according to standard histological methods. Serial paraffin sections of $4 \mathrm{~mm}$ were stained with hematoxylin eosin and observed at $400 \mathrm{X}$ magnification for any significant change in reproductive organs.

\section{Safety studies \\ Effect of $r$ SAF on local toxicity}

To appraise the local toxic effect of rSAF, six female $\mathrm{BALB} / \mathrm{c}$ mice were divided into two groups viz. control and treated (3 animals each). rSAF at a dose of $5 \mu \mathrm{g} /$ day/ animal was administered intravaginally for 14 successive days. All animals were weighed on the first day of dosing and every seventh day thenceforth. The animals were checked at least twice daily for morbidity/mortality. Examination was also carried out for vaginal bleeding and discharges after 0.5 and $4 \mathrm{~h}$ after dosing. All the three animals of the control group received $0.1 \mathrm{ml}$ of phosphate buffered saline (PBS). On day 15, animals from each group were sacrificed. The kidney, liver, spleen, ovary, uterus, and vagina were excised, fixed, and examined histologically [33].

\section{Effect of rSAF on general health of mice}

Female mice were divided into two groups (control and treated) of three animals each. rSAF was administered orally with the help of gavage once daily, at a dose level of 1 $\mathrm{mg} / \mathrm{kg}$ body weight for 14 days to the treated group, at the same time the control group received PBS. On day 15, animals from each group were sacrificed. The nonreproductive (liver, kidney and spleen) and reproductive organs (ovaries and uterus) were removed and fixed in formalin. The sections were stained with hematoxylin and eosin, and evaluated for microscopic pathologic changes. Also, tissue somatic indices (TSI) (percent organ weight in relation to bodyweight) of reproductive and nonreproductive tissues of mice were recorded $24 \mathrm{~h}$ after the completion of 14 day oral administration of rSAF [12].

\section{Primary dermal irritation test}

Five micrograms and $25 \mu \mathrm{g}$ of rSAF (test) or PBS (control) were applied topically once daily $(50 \mu \mathrm{l} /$ site/animal $)$ for 5 consecutive days, to one non abraded and one abraded test site per mice. Each group consisted of 3 mice. The test site was throttled by covering each site with a gauze pad and over wrapping the site with plastic wrap. On day 6, dermal irritation was scored according to the Draize scoring system [34].

\section{Penile mucosal irritation test}

Five micrograms and $25 \mu \mathrm{g}$ of rSAF or PBS (placebo) were applied directly $(50 \mu \mathrm{l} / \mathrm{site} / \mathrm{animal})$ to the penis of three mature male BALB/c mice hourly for $4 \mathrm{~h}$ on 3 consecutive days. Each group consisted of three mice. All animals were observed for erythema and eschar formation prior to the application of the test material and 
at 1, 24, and $48 \mathrm{~h}$ after the last application [35]. The penises were dissected at the base of the pelvis (leaving the sheath intact), evaluated for gross pathology, and fixed in formalin. Sections from the fixed penises were blocked, sectioned, stained with hematoxylin and eosin, and evaluated for microscopic pathologic changes.

\section{Results}

\section{S. warneri agglutinates human spermatozoa}

A clinical isolate obtained from the cervix of a woman with inexplicable infertility agglutinated human spermatozoa in vitro (Fig. 1a, b). The isolate was identified as $S$. warneri by MALDI with log score 2.4. Whole culture and cells washed with saline agglutinated the spermatozoa whereas the culture supernatant did not. Sperm agglutination occurred in all possible orientation viz. in headhead, head-tail and tail-tail.

Cloning of sperm agglutinating factor in E. coli Construction of genomic library, screening of transformants and in silico analysis of SAF

In genomic library, a total of $3 \times 10^{5}$ transformants were obtained and were screened for their sperm agglutinating

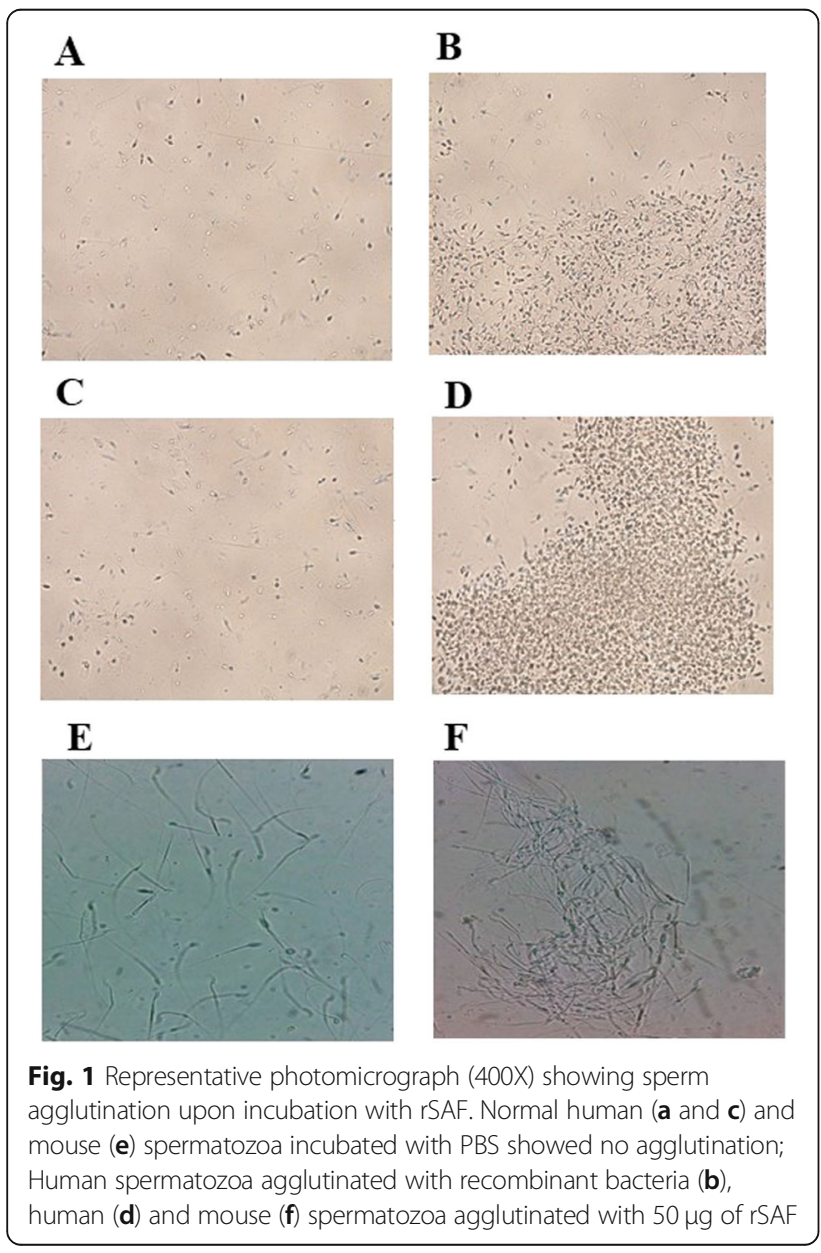

activity (Additional file 1: Figure S1a, b). Recombinant plasmid from positive transformant was isolated and the insert was sequenced using vector primers SL1 and SR2 (forward and reverse) and a $2903 \mathrm{bp}$ insert sequence was obtained (Additional file 1: Figure S2). ORF finder showed the presence of one ORF encoding ribonucleotidediphosphate reductase- $\alpha$ sub unit. STRING analysis showed the proteins interacting with ribonucleotidediphosphate reductase- $\alpha$ [24].

ProtParam online tool was used to predict physicochemical parameters of ribonucleotide-diphosphate reductase- $\alpha$ (Additional file 1: Table S1). Secondary structure (Additional file 1: Figure S3) of ribonucleotidediphosphate reductase- $\alpha$ is composed of alpha helices (291 amino acids), beta-sheets (106 amino acids) and random coils (304 amino acids). SWISS Model online tool was used to predict three dimensional structure of Ribonucleotide-diphosphate reductase- $\alpha$ sub unit using ribonucleotide reductase class $1 \mathrm{~b}$ holocomplex R1E, R2F from Salmonella typhimurium (2bq1.1.B) with 42.39\% identity as the closest template (Fig. 3a). Structure was validated by RAMPAGE and 631 (92.4\%) residues were found in favourable, 35 (5.1\%) in disallowed and 17 $(2.5 \%)$ in outlier region (Additional file 1: Figure S4) showing its good quality stereochemical structure.

\section{Expression and purification of rSAF under native conditions} Ribonucleotide-diphosphate reductase- $\alpha$ was sub cloned in pET-28a and expressed in E. coli BL21 (DE3) by induction with $1 \mathrm{mM}$ IPTG at $37^{\circ} \mathrm{C}$ for $5 \mathrm{~h}$. Soluble protein was purified by Ni-NTA affinity chromatography under native conditions up to a concentration of $40 \mathrm{mg} / \mathrm{L}$ and resolved on SDS-PAGE (Fig. 2a). Quality of purified recombinant SAF was checked by Circular dichorism (Fig. 3b). Recombinant SAF (Ribonucleotide-diphosphate reductase- $\alpha$ sub unit) showed the sperm agglutinating activity when incubated with human and mouse sperms (Fig. 1c-f).

\section{Binding of rSAF to spermatozoa}

Fluorescence microscopy post treatment of sperm samples with FITC labelled rSAF revealed the presence of bright green fluorescence over the entire surface of spermatozoa depicting the binding of rSAF with spermatozoa and the fluorescence showed the presence of receptors on the entire surface of spermatozoa to which rSAF binds (Fig. 2c, d).

\section{In vitro effect of $r S A F$ on spermatozoa $\mathrm{Mg}^{2+}$-ATPase}

In a dose-dependent manner, rSAF inhibited $\mathrm{Mg}^{2+}$ ATPase activity of human and mouse spermatozoa (Fig. 2b). At concentrations of $12.5 \mu \mathrm{g}$ and $25 \mu \mathrm{g}, \mathrm{Mg}^{2+}$ ATPase activity declined from $1211.17 \pm 9.3$ units (control) to $532.93 \pm 7.85(44 \%)$ and $271.45 \pm 7.69$ (22.4\%) 


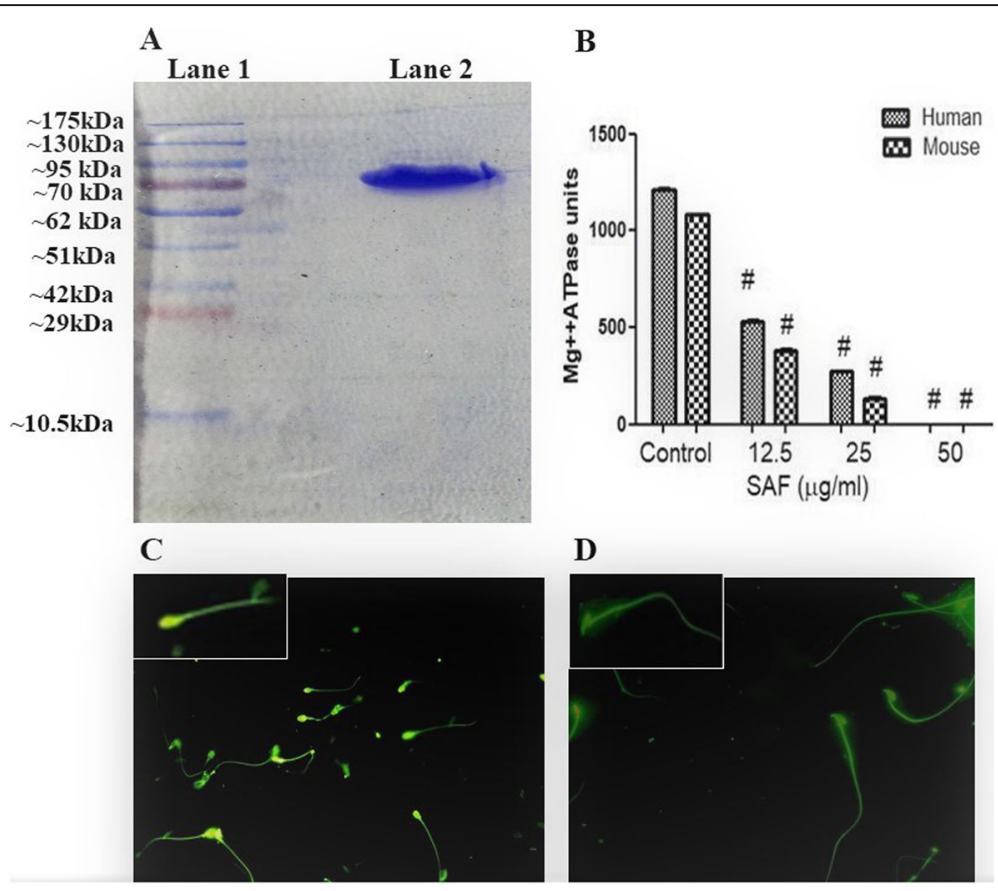

Fig. 2 a Estimation of molecular weight of recombinant SAF. Lane 1: Pink plus Protein molecular weight marker; Lane 2: Purified recombinant SAF. $\mathbf{b}$ Inhibition of $\mathrm{Mg}^{++}$dependent ATPase activity of human spermatozoa and mouse spermatozoa upon incubation with rSAF (0-50 $\left.\mu \mathrm{g}\right)$. The results shown are mean \pm S.D. of three observations, $\# p<0.001$. (H:human; M:mouse) (c) Visualization of FITC labeled recombinant rSAF incubated with human and $\mathbf{d}$ mouse spermatozoa by fluorescent microscopy (400X) showing rSAF binding to spermatozoa

units, respectively. When rSAF was added at higher concentration i.e. $50 \mu \mathrm{g}$ of SAF, no detectable $\mathrm{Mg}^{2+}$-ATPase activity could be observed. The effect of rSAF on the $\mathrm{Mg}^{2+}$-ATPase activity of mouse spermatozoa also displayed similar trend with $\mathrm{rSAF}$ at $50 \mu \mathrm{g}$ showing maximum inhibition of $\mathrm{Mg}^{2+}$-ATPase activity. The units decreased from $1083.4 \pm 9.07$ (control) to $634.73 \pm 4.79$ (58.54\%), $389.2 \pm 3.16(35.9 \%)$ and $144.51 \pm 7.31(13.33 \%)$ when incubated with rSAF at concentrations of $6.25,12.5$ and $25.0 \mu \mathrm{g}$, respectively.
A

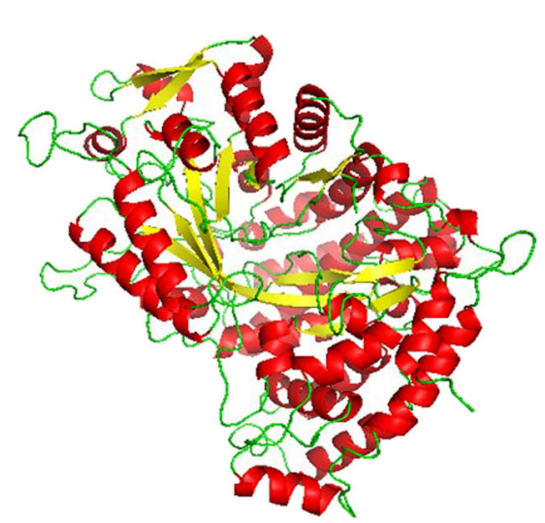

B

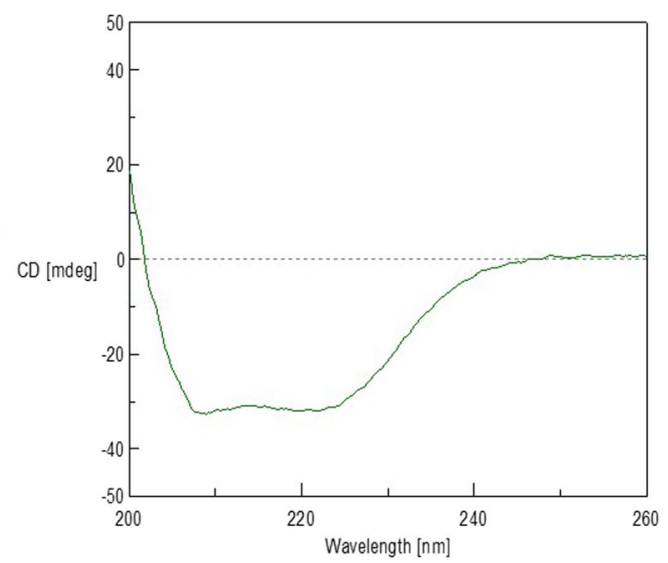

Fig. 3 a 3-D structure of SAF modeled with SWISS-MODEL using homology modeling based on the template ribonucleotide reductase class $1 \mathrm{~b}$ holocomplex R1E, R2F from Salmonella typhimurium (PDB ID: 2bq1.1.B) (b) CD spectra of recombinant SAF protein purified by Ni-NTA chromatography. The far UV CD spectrum of SAF protein analyzed by $k 2 \mathrm{~d} 2$ software revealed that the secondary structure contained $49 \%$ a-helix, $17.8 \% \beta$-strand and $33.2 \%$ random coil 
In vitro effect of rSAF on human spermatozoan morphology and acrosome status

Scanning electron microscopy (SEM) showed that rSAF reacted with spermatozoa resulting in distortion of its head (Fig. 4a, b). Further, effect of rSAF $(25 \mu \mathrm{g})$ on human sperm acrosome status was analysed and two patterns of fluorescence were observed. The spermatozoa with bright green fluorescence on more than half of the head indicated intact acrosomes (AI), whereas spermatozoa with only a fluorescing band at the equatorial segment were interpreted as acrosome-reacted (AR) (Fig. 4c). Upon incubation of spermatozoa with rSAF, it was observed that rSAF could lead to premature acrosome reaction (Ar) to the extent of $84.5 \pm 1.8 \%$. However, in case of negative control (DMSO) percentage of acrosome reacted spermatozoa was $12.66 \pm 1.5 \%$. The results obtained in case of rSAF were comparable to that induced by calcium ionophore $(90.66 \pm 1.60 \%)$, (positive control) (Fig. 4d).

\section{Contraceptive efficacy of rSAF}

The control group mice (administered with PBS) displayed consistent weight gain, abdominal distension along with palpation of string of pearls and at the end of gestation period, delivered pups. rSAF when administered at lower concentration $(2.5 \mu \mathrm{g})$ showed results comparable to control group (Fig. 5). However, all these changes were absent in group of mice receiving rSAF at concentrations $\geq 5 \mu \mathrm{g}$, indicating its excellent in vivo contraceptive efficacy (Table 1).

\section{Histology}

Further, the histological evaluation of reproductive organs of mice was carried out to observe the pregnancy associated changes on days 0 and 14 . In case of both control and rSAF treated groups, ovary and uterus showed normal tissue histology on day 0 before mating. However, on day 14 post mating, development of corpus luteum in ovaries was observed that indicated luteal phase were observed only in case of control mice and the group receiving lower concentration of rSAF i.e. $2.5 \mu \mathrm{g}$. In uterus, stromal decidualization and thickening of endometrium followed by proliferation and differentiation of uterine endometrium showed all the pregnancy related changes. All these pregnancy related alterations were absent in groups of mice instilled with higher concentrations rSAF viz. $5 \mu \mathrm{g}$ and $10 \mu \mathrm{g}$ (Fig. 6).

\section{Safety studies}

\section{Effect of rSAF on local toxicity in mice}

Vaginal irritation studies performed in mice revealed no significant changes in mean body weight among the treatment groups ( $5 \mu \mathrm{g} \mathrm{rSAF}$ ) or untreated groups (PBS). Also, no differences were observed among the treatment and control groups in terms of gross observations of the organs at necropsy and organ weights. Further, no
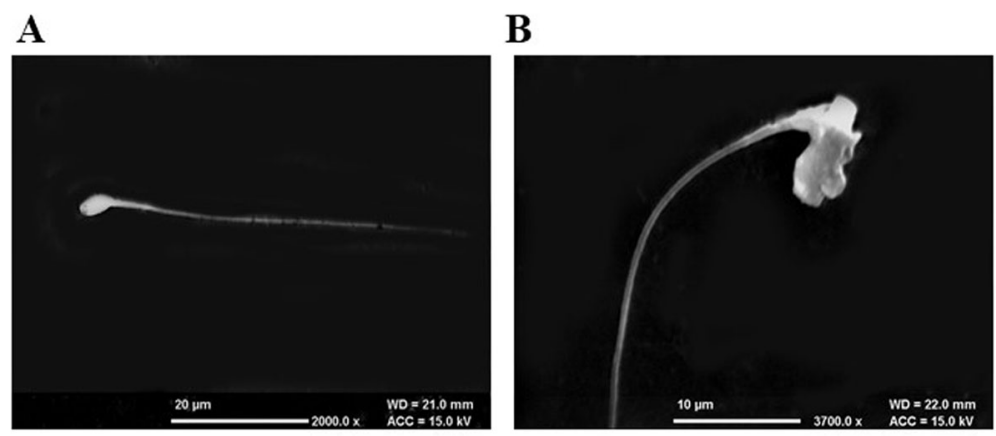

C

D
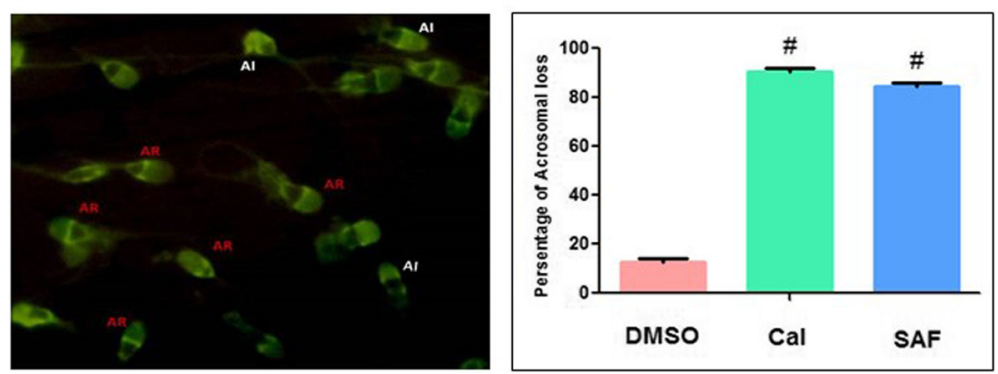

Fig. 4 Scanning electron micrographs of human spermatozoan. a normal b treated with rSAF (100 $\mu$ g,1 h) showing distortion of head. c Representative photomicrograph showing acrosome reacted (AR) and acrosome intact (Al) human spermatozoa as observed by fluorescence microscopy (400X) (d) Percentage of acrosome reacted spermatozoa after incubation with (0.1\%) DMSO or (10 $\mu \mathrm{g})$ Cal A23187 or SAF (25 $\mu \mathrm{g})$. The values shown are mean \pm SD of three observations, \#p<0.001 

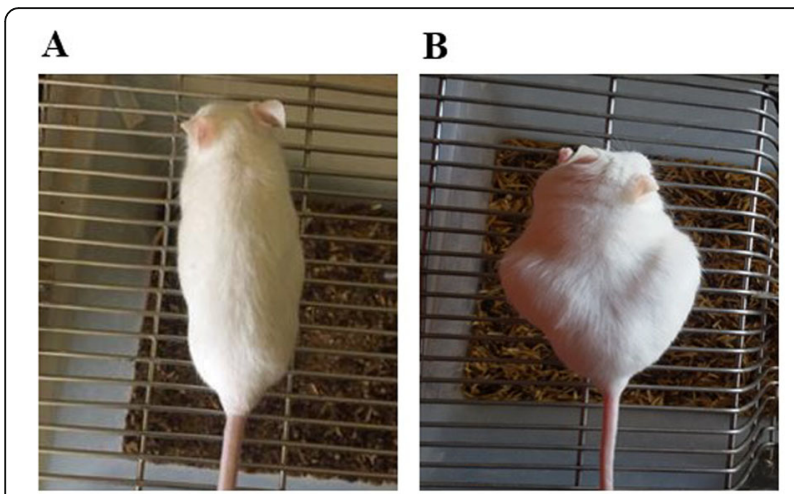

C

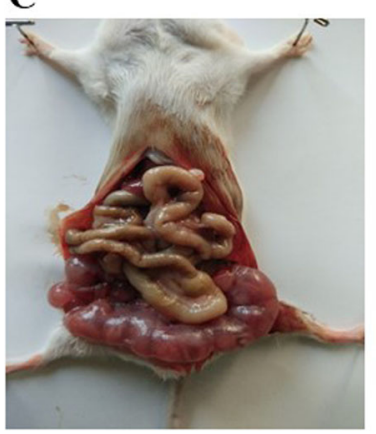

D

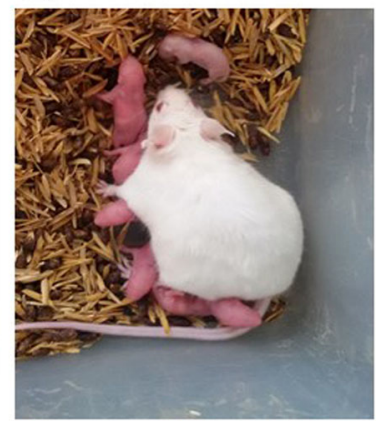

Fig. 5 Representative photographs of pregnancy-related changes in female BALB/C mice instilled with PBS/2.5 $\mu \mathrm{g}$ rSAF (a) Day 0 of gestation (b) Day 22 showing abdominal distension, (c) with string of pearls on day 14 of gestation (d) delivery of pups at the end of gestation period

change in the histology of reproductive organs and vital non-reproductive organs of mice was observed with respect to control mice (Additional file 1: Figures S5, S6). The mouse vagina was also studied for histopathological changes and no histological alterations could be attributed to rSAF. There was no edematous thickening of the submucosal layer or infiltration of polymorphonuclear leucocytes in to the mucosa. Thus, rSAF did not produce local toxicity in mice following vaginal application for a 14-day period.

\section{Effect of rSAF on general health of mice and on tissue somatic indices}

During the 14 day oral treatment, no behavioural changes (such as lethargy, aggression etc.) were observed in the

Table 1 Effect of rSAF on fertility outcome in female mice

\begin{tabular}{|c|c|c|}
\hline $\begin{array}{l}\text { rSAF dose instilled ( } \mu \mathrm{g} / \\
20 \mu \mathrm{l})\end{array}$ & $\begin{array}{l}\text { Number of female mice per } \\
\text { group }\end{array}$ & $\begin{array}{l}\text { Fertility } \\
\text { outcome }\end{array}$ \\
\hline PBS & 3 & $\begin{array}{l}3 / 3 \\
(100 \%)\end{array}$ \\
\hline $2.5 \mu \mathrm{g}$ of $\mathrm{rSAF}$ & 5 & $\begin{array}{l}5 / 5 \\
(100 \%)\end{array}$ \\
\hline $5 \mu \mathrm{g}$ of $\mathrm{rSAF}$ & 5 & $0 / 5(0 \%)$ \\
\hline $10 \mu \mathrm{g}$ of rSAF & 5 & $0 / 5(0 \%)$ \\
\hline
\end{tabular}

treated mice. After the completion of 14 day oral treatment with rSAF, no change in the tissue histology of reproductive and non-reproductive organs of mice was observed in comparison to control mice. Further, the \% TSI also showed no significant change in the weight of the organs of treated group in comparison to control group (Additional file 1: Table S1).

\section{Dermal irritation test}

No treatment related changes (edema, erytherma or eschar formation) were observed in any of the mice at $24 \mathrm{~h}, 48 \mathrm{~h}$ and $72 \mathrm{~h}$ examination points after application of rSAF for 5 consecutive days (Additional file 1: Figure S7). Therefore, rSAF was considered as non irritating to the skin.

\section{Penile mucosal irritation test}

Penile irritation studies in mice revealed no gross morphological or histopathological changes attributed to rSAF at $5 \mu \mathrm{g}$ or $25 \mu \mathrm{g}$ concentration (Additional file 1: Figure S8) in comparison to placebo.

\section{Discussion}

According to the United Nations, the world population will reach 11.2 billion by the year 2100 [36] and contraception is the key solution to thwart this problem. Contraceptive methods to control the population are aplenty and many more are in pipeline. Condoms, intrauterine devices and oral contraceptives are successful tools available since long but they are associated with number of limitations, hence, there is an urgent need to develop safe, inexpensive and highly effective contraceptive methods. In this regard, sperm impairing agents or spermicides have come into light. Any sperm impairing agent, which immediately and irreversibly agglutinates or immobilizes the spermatozoa, not affecting developing foetus, non-irritating to penile and vaginal mucosa, non-toxic and not absorbed systemically could be a boon to field of contraception.

Various pathogens have been isolated from the semen of infertile and fertile patients interacting with the spermatozoa in terms of their agglutination and morphologic alterations [18-23]. These pathogens are causative agents of genitourinary infections and affect the functioning of spermatozoa by reducing their motility and damaging their structure [37]. Moretti et al. (2009) reported that E. coli elicits detrimental effect on spermatozoa such as swelling of mid-piece and tail invagination [38]. Also, they suggested the binding of $E$. coli on spermatozoa and its subsequent destruction in a two-step process [39]. Paulson and Polakoski, (1977) proposed a mechanism of sperm immobilization by $E$. coli and a factor excreted by $E$. coli that immobilized spermatozoa without agglutinating it [40]. Similarly, Diemer et al., (1996) reported that binding 
A

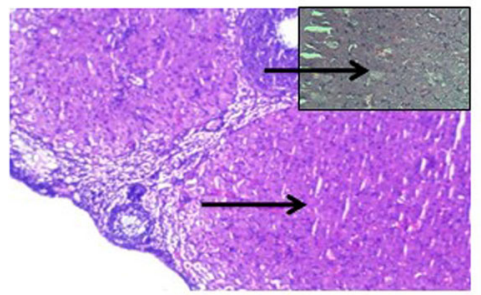

C

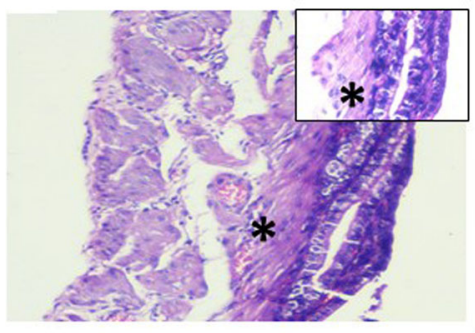

B

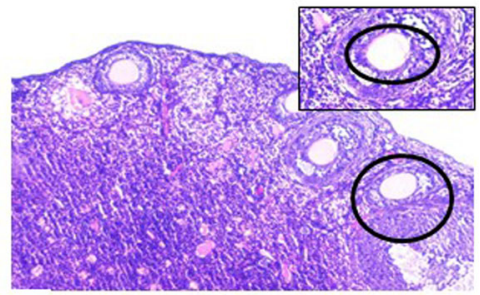

D

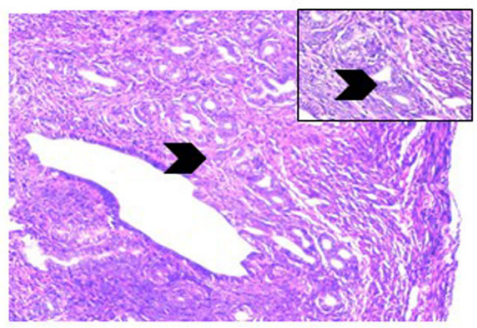

E

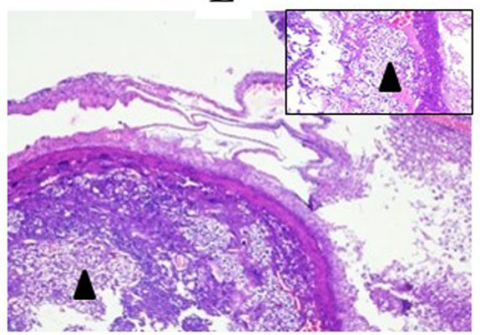

Fig. 6 Histology of female reproductive organs on gestation day 14 in mice treated with PBS (controls: a, c, e) or $5 \mu$ g of recombinant SAF (tests: b, d). a Control ovary (arrow is showing the presence of corpus luteum); c control uterus (asterisk is showing the presence of deciduas $\mathrm{E}$ ), e) placenta (triangle is showing the trophoblastic cells). rSAF treated (b) ovary (circle is showing graafian follicles), $\mathbf{d}$ uterus (arrow head is showing the normal muscles without any deciduas, as no pregnancy related changes were observed. Original magnification 100X, the predominant aspect is shown in the inset (400X)

of $E$. coli results in inhibition of sperm motility via sperm agglutination [37]. Mannose has been found to interfere with binding of $E$. coli to spermatozoa but exact mechanisms of bacterial and sperm interactions have not been identified [41]. S. aureus has also been found as predominant flora in semen of infertile men and causes infertility by reducing sperm motility [42]. Emokpae et al. (2009) found S. aureus as major contributor in seminal infections [43]. Ohri and Prabha (2005) reported S. aureus to cause sperm agglutination and an unknown protein as sperm agglutinating factor from this bacterium has been proposed responsible for this phenomenon [44].

Role of microorganisms in impairing sperm motility is well known; hence microorganisms from the cervix of a woman with unexplained infertility were obtained and screened for sperm agglutinating activity in vitro. Clinical isolates showing positive sperm agglutinating activity were identified by MALDI. S. warneri was the organism impairing sperm function and is a close homologue of $S$. aureus, reported as sperm agglutinating agent [45]. $S$. warneri was evaluated for sperm agglutinating activity and it was found that whole culture and bacterial cells washed with saline were able to agglutinate the sperm but culture supernatant could not. Sperm agglutination occurred in head-head, head-tail and tail-tail orientations that shows the presence of receptors on whole sperm. Ribonucleotide-diphosphate reductase- $\alpha$ sub unit gene was identified by creating shotgun genomic library that was further over expressed and purified.

Motility, acrosome status and morphology are the main parameters to determine fertilization potential of spermatozoa. Any agent interferes with any of these parameters could be exploited as contraceptive. Therefore, all these three parameters were studied by incubating sperm with rSAF and it agglutinated sperm resulting in immobilization in vitro. Complete arrest of sperm motility has been reported within 20s using $100 \mu \mathrm{g}$ SAF as compared to $400 \mu \mathrm{g}$ nisin [12] and $1 \mathrm{mg}$ magainin-A indicating higher efficiency of SAF [46]. Interestingly, Kaur and Prabha reported the irreversible effect of SAF on sperm motility as spermatozoa incubated with SAF remained immotile even after removing SAF from the 
reaction [47]. This showed the irreversibility of binding and possible cytotoxicity exerted by SAF. Moreover, incubation with SAF led to the complete loss of sperm viability at high concentrations within 20 s showing the efficacy and rapidity of SAF mediated sperm damage. Interestingly, effects of SAF can be neutralized by antiSAF antiserum to inverse the infertility. Kaur et al. (2013) raised the anti-SAF antibodies and found that in the presence of antibodies, sperm agglutination was blocked by inhibiting the binding of SAF to spermatozoa thus leading to conception in mouse model [48].

Motility is the most important character of spermatozoa required for the fertilization as immotile spermatozoa fail to meet oocyte and fertilization is inhibited. ATP provided by mitochondrian is required for sperm motility to power spermatozoa to the site of fertilization [49]. Cation dependent ATPases are responsible for the flagellar contractile processes and active transport [50]. Sperm moves due to ATP hydrolysis catalyzed by dyenin ATPase that is an $\mathrm{Mg}^{2+}$ dependent enzyme located on axoneme [51]. There is a direct correlation between the sliding velocity and the quantity of dyenin arm present on the axoneme [52]. Therefore, inhibition of $\mathrm{Mg}^{2+} \mathrm{de}-$ pendent ATPase is an important parameter while studying sperm function as it is the primary sperm motility regulatory step. Hence, effect of rSAF on $\mathrm{Mg}^{2+}$ dependent ATPase activity was analyzed and the results showed that rSAF acted as potent inhibitor of enzyme and decreased the activity in a concentration dependent manner. This inhibition of sperm $\mathrm{Mg}^{2+}$ dependent ATPase could be implicated as one of the mechanisms of impairing sperm motility by rSAF.

Premature acrosome reaction and acrosome reaction failure are crucial aspects of sperm function and are considered as important causes of infertility. The acrosome reaction is a receptor mediated exocytic process that involves outer acrosomal membrane and the sperm plasma membrane resulting in release of acrosomal enzymes required for fertilization [53]. The sperm with intact acrosome reaching the egg is required for fertilization that undergoes induced acrosome reaction on the surface of the zona pellucida [54]. Spermatozoa bind to zona pellucida and oocyte along with its surrounding cells release progesterone resulting in induction of acrosome reaction. Spermatozoa in cervix/vagina losing their acrosome prematurely lose their fertilization ability resulting in infertility [55]. Kaur et al. reported the inducing effect of SAF on premature AR and apoptosis in spermatozoa [56]. Therefore, acrosome status was analysed by incubating spermatozoa and rSAF that resulted in significantly higher rate of acrosome reaction and was comparable to $\mathrm{CaI}$ (positive control) when observed by fluorescent microscopy, proving its involvement in sperm damage. rSAF was found to induce premature $\mathrm{AR}$ in spermatozoa thus, decreasing its fertilization potential.

To understand the interaction between $\mathrm{rSAF}$ and spermatozoa, binding studies were carried out. When FITC labelled rSAF was incubated with human and mouse spermatozoa, fluorescence was observed over the entire spermatozoa indicating that receptors for rSAF are present on whole body i.e. sperm head, neck and tail. The uniform distribution of receptor on head, tail and body of spermatozoa resulted in mixed type of agglutination (head-tail, tail-tail and head-head). Further, intravaginal inoculation of rSAF in mice resulted in blockage of fertility was evident by absence of pregnancy related changes when observed apparently and histologically. Subsequent to assessing the contraceptive efficacy of the rSAF its toxicological impacts were likewise considered and rSAF was found to cause no toxicological effects at the contraceptive dose.

\section{Conclusion}

The present study suggests that rSAF possessed admirable spermicidal activity in vitro and excellent contraceptive efficacy in vivo. Further, its high safety profile makes it a potential candidate to be developed as an effective vaginal contraceptive in future.

\section{Supplementary information}

Supplementary information accompanies this paper at https://doi.org/10. 1186/s12958-019-0531-6.

Additional file 1. Supporting data.

\begin{abstract}
Abbreviations
Al: Intact acrosomes; AMPs: Antimicrobial peptides; AR: Acrosome-reacted; Ar: Premature acrosome reaction; DMSO: Dimethyl sulfoxide; IPTG: Isopropyl $\beta$-D-1-thiogalactoside; LB: Luria Broth; MALDI: Matrix-assisted laser desorption/ionization; PBS: Phosphate buffer saline; PCR: Polymerase chain reaction; Pi: Inorganic phosphorus; PSA-FITC: Pisum sativum agglutininFluorescein isothiocyanate; rSAF: Recombinant sperm agglutinating factor; SAF: Sperm agglutinating factor; TCA: Trichloroacetic acid
\end{abstract}

\section{Acknowledgements \\ We would like to thank Dr. B. N. Dutta (Retd. Pathologist, PGIMER, \\ Chandigarh, India) for the histological analysis.}

\section{Authors' contributions}

NCP performed all the experiments and wrote the manuscript; RS, VG \& AC assisted in the experimental work and manuscript writing; RM provided semen samples and assisted in experimental work; VP \& PS conceived the idea, guided the experiments and edited the manuscript. All authors read and approved the final manuscript.

\section{Funding}

The authors thank Department of Science and Technology, New Delhi, India (grant no DST/Inspire Fellowship/2012/716) for the funding.

Availability of data and materials

All data generated or analysed during this study are included in this article. 


\section{Ethics approval}

The experimental protocols for human semen were approved by the Institutional Ethics Committee, PGIMER, Chandigarh, vide letter number IEC08/2017-678 and were carried out in accordance with the committee's guidelines. An informed consent was obtained from all the subjects before participation in the study.

The animal experimental protocols were approved by the Institutional Animal Ethics Committee of the Panjab University, Chandigarh, India vide letter no. PU/IAEC/S/15/72 and were performed in accordance with the guidelines of the Committee for the Purpose of Control and Supervision of Experiments on Animals (CPCSEA).

\section{Consent for publication}

Not applicable

\section{Competing interests}

The authors declare that they have no competing interests.

\section{Author details}

'Department of Microbiology, South Campus, Basic Medical Science (Block I), Panjab University, Sector 25, Chandigarh 160014, India. ${ }^{2}$ Department of Urology, PGIMER, Chandigarh, India.

Received: 24 June 2019 Accepted: 2 October 2019

\section{Published online: 27 October 2019}

\section{References}

1. Abel GJ, Barakat B, KC S, Lutz W. Meeting the sustainable development goals leads to lower world population growth. Proc Natl Acad Sci. 2016;113: 14294-9 Available from: http://www.pnas.org/lookup/doi/10.1073/ pnas.1611386113.

2. Herndon EJ, Zieman M. New contraceptive options. Am Fam Physician. 2004;69:853-60

3. Shoupe D. LARC methods: entering a new age of contraception and reproductive health. Contracept Reprod Med. 2016;1:4. https://doi.org/10. 1186/s40834-016-0011-8.

4. Gilliam ML, Derman RJ. Barrier methods of contraception. Obstet Gynecol Clin. 2000;27:841-58.

5. Curtis KM, Mohllajee AP, Peterson HB. Regret following female sterilization at a young age: a systematic review. Contraception. 2006;73:205-10.

6. Tanphaichitr N, Srakaew N, Alonzi R, Kiattiburut W, Kongmanas K, Zhi R, et al. Potential use of antimicrobial peptides as vaginal spermicides/ microbicides. Pharmaceuticals. 2016:9:13.

7. Mukherjee M, Datta M, Biswas S, Pal AK, Malakar D, Bhattacharyya AK, et al. Immotilin, a novel sperm immobilizing protein. Fertil Steril. 2003;79:1673-5.

8. Shah HC, Tatke P, Singh KK. Spermicidal agents. Drug Discov Ther. 2008;2: 200-10 Available from: http://www.ncbi.nlm.nih.gov/pubmed/22504630.

9. Reddy VRK, Manjramkar DD. Evaluation of the antifertility effect of magainina in rabbits: in vitro and in vivo studies. Fertil Steril. 2000;73:353-8.

10. Clara A, Manjramkar DD, Reddy VK. Preclinical evaluation of magainin-a as a contraceptive antimicrobial agent. Fertil Steril. 2004;81:1357-65.

11. Aranha C, Gupta S, Reddy KVR. Contraceptive efficacy of antimicrobial peptide Nisin: in vitro and in vivo studies. Contraception. 2004;69:333-8.

12. Reddy KVR, Aranha C, Gupta SM, Yedery RD. Evaluation of antimicrobial peptide nisin as a safe vaginal contraceptive agent in rabbits: in vitro and in vivo studies. Reproduction. 2004;128:117-26.

13. Gupta SM, Aranha CC, Bellare JR, Reddy KVR. Interaction of contraceptive antimicrobial peptide nisin with target cell membranes: implications for use as vaginal microbicide. Contraception. 2009;80:299-307.

14. Sutyak KE, Anderson RA, Dover SE, Feathergill KA, Aroutcheva AA, Faro S, et al. Spermicidal activity of the safe natural antimicrobial peptide subtilosin. Infect Dis Obstet Gynecol. 2008;2008:540758.

15. Murty GSRC, Sheela Rani CS, Moudgal NR, Prasad MRN. Effect of passive immunization with specific antiserum to $\mathrm{FSH}$ on the spermatogenic process and fertility of adult male bonnet monkeys (Macaca radiata). J Reprod Fertil. 1979;1979(Suppl. 26):174-63.

16. Govind CK, Gupta SK. Failure of female baboons (Papio anubis) to conceive following immunization with recombinant non-human primate zona pellucida glycoprotein-B expressed in Escherichia coli. Vaccine. 2000;18: 2970-8.
17. Purswani S, Talwar GP. Development of a highly immunogenic recombinant candidate vaccine against human chorionic gonadotropin. Vaccine. 2011;29: 2341-8.

18. Bartoov B, Ozbonfil D, Maayan MC, Ohad E, Nitzan Y. Virulence characteristics of male genital tract Escherichia coll isolated from semen of suspected infertile men. Andrologia. 1991;23:387-94.

19. Hosseinzadeh S, Brewis I a, Eley A, Pacey AA. Co-incubation of human spermatozoa with chlamydia trachomatis serovar E causes premature sperm death. Hum Reprod. 2001;16:293-9.

20. Svenstrup HF, Fedder J, Abraham-Peskir J, Birkelund S, Christiansen G. Mycoplasma genitalium attaches to human spermatozoa. Hum Reprod. 2003;18:2103-9.

21. Peerayeh SN, Yazdi RS, Zeighami H. Association of Ureaplasma urealyticum infection with varicocele-related infertility. J Infect Dev Ctries. 2008;2:116-9.

22. Prabha V, Gupta T, Kaur S, Kaur N, Kala S, Singh A. Isolation of a spermatozoal immobilization factor from Staphylococcus aureus filtrates. Can J Microbiol. 2009:55:874-8.

23. Tian YH, Xiong JW, Hu L, Huang DH, Xiong CL. Candida albicans and filtrates interfere with human spermatozoal motility and alter the ultrastructure of spermatozoa: an in vitro study. Int J Androl. 2007;30:421-9.

24. Pant NC, Singh R, Chauhan A, Gupta V, Mavuduru RS, Prabha V, et al. Contraceptive sperm agglutinating proteins identified in Staphylococcus warneri, natural microflora of an infertile woman. Indian J Microbiol. 2018; 59:51-7.

25. Sambrook J, Fritsch EF, Maniatis T. Molecular cloning: a laboratory manual. New York: Cold Spring Harbor laboratory press; 1989. p. 931-57.

26. Singh R, Capalash N, Sharma P. Immunoprotective potential of BamA, the outer membrane protein assembly factor, against MDR Acinetobacter baumannii. Sci Rep. 2017;7:12411.

27. Laemmli UK. Cleavage of structural proteins during the assembly of the head of bacteriophage T4. Nature. 1970;227:680-5.

28. Hafez ESE, Kanagawa H. Scanning electron microscopy of human, monkey and rabbit spermatozoa. Fertil Steril. 1973;24:776-87.

29. Kielly NW. Mitochondrial ATPase. In: Cold wick SP, Kaplan NO, editors. Methods in Enzymology, vol. II. New York: Academic; 1955.

30. Chappel J. Effect of alkylguanidine on mitochondrial metabolism. J Biol Chem. 1963;238:410-7.

31. Boyce A, Casey A, Walsh G. A phytase enzyme-based biochemistry practical particularly suited to students undertaking courses in biotechnology and environmental science. Biochem Mol Biol Educ. 2004;32:336-40.

32. Whitten WK. Modification of the oestrous cycle of the mouse by external stimuli associated with the male. J Endocrinol. 1956:13:399-404.

33. Kaur S, Prabha V, Kaur K. Safety studies of sperm agglutinating factor produced by Staphylococcus aureus as a vaginal contraceptive: in vivo studies. Gynecol Endocrinol Taylor \& Francis. 2011;27:956-60.

34. Draize J. Dermal toxicity. In: Topeka KS, editor. Appraisal of the safety of chemicals in foods, drugs and cosmetics. New York: Association of food drug officials of the united states; 1965.

35. Zaneveld LJD, Waller DP, Anderson RA, Chany C, Rencher WF, Feathergill K, et al. Efficacy and safety of a new vaginal contraceptive antimicrobial formulation containing high molecular weight poly(sodium 4Styrenesulfonate)1. Biol Reprod. 2002;66:886-94.

36. World Population Prospects - Population Division - United Nations. Available from: https://population.un.org/wpp/

37. Diemer T, Weidner W, Michelmann HW, Schiefer HG, Rovan E, Mayer F. Influence of Escherichia coli on motility parameters of human spermatozoa in vitro. Int J Androl. 1996;19:271-7.

38. Moretti E, Capitani S, Figura N, Pammolli A, Federico MG, Giannerini V, Collodel $\mathrm{G}$. The presence of bacteria species in semen and sperm quality. J Assist Reprod Genet. 2009;26:47-56.

39. Diemer T, Huwe P, Ludwig M, Schroeder-Printzen I, Michelmann HW, Schiefer $\mathrm{HG}$, et al. Influence of autogenous leucocytes and Escherichia coli on sperm motility parameters in vitro. Andrologia. 2003:35:100-5.

40. Paulson JD, Polakoski KL. Isolation of a spermatozoal immobilization factor from Escherichia coli filtrates. Fertil Steril. 1977;28:182-5.

41. Wolff H, Panhans A, Stolz W, Meurer M. Adherence of Escherichia coli to sperm: a mannose mediated phenomenon leading to agglutination of sperm and E. coli. Fertil Steril. 1993;60:154-8.

42. Esmailkhani A, Akhi MT, Sadeghi J, Niknafs B, Bialvaei AZ, Farzadi L, et al. Assessing the prevalence of Staphylococcus aureus in infertile male patients 
in Tabriz, northwest Iran. Int J Reprod Biomed. 2018;16:469 Shahid Sadoughi University of Medical Sciences and Health Services.

43. Emokpae M, Uadia P, Sadiq N. Contribution of Bacterial Infection to Male Infertility in Nigerians. 2009; Dr. BS Kakkilaya; Available from: http://cogprints. org/6564/

44. Ohri M, Prabha V. Isolation of a sperm-agglutinating factor from Staphylococcus aureus isolated from a woman with unexplained infertility. Fertil Steril. 2005;84:1539-41.

45. Kaur S, Prabha V. Infertility as a Consequence of Spermagglutinating Staphylococcus aureus Colonization in Genital Tract of Female Mice. PLoS One. 2012;7:e52325 Sawtell NM, editor. Public Library of Science.

46. Reddy KVR, Shahani SK, Meherji PK. Spermicidal activity of magainins: in vitro and in vivo studies. Contraception. 1996;53:205-10.

47. Kaur S, Prabha V. Receptor mediated amelioration of the detrimental effects of sperm agglutinating factor on sperm parameters. Andrology. 2013;1:624-31.

48. Kaur K, Rishi P, Prabha V. Amelioration of sperm agglutinating factor (SAF) induced sperm impairment by anti-SAF polyclonal antibody. Andrology. 2013:2:109.

49. Bahr GF, Engler WF. Considerations of volume, mass, DNA, and arrangement of mitochondria in the midpiece of bull spermatozoa. Exp Cell Res. 1970;60: 338-40.

50. Harper CC, Cheong M, Rocca CH, Darney PD, Raine TR. The effect of increased access to emergency contraception among young adolescents. Obstet Gynecol. 2005;106:483-91.

51. Gibbons BH, Gibbons IR. Properties of flagellar "rigor waves" formed by abrupt removal of adenosine triphosphate from actively swimming sea urchin sperm. J Cell Biol. 1974;63:970-85.

52. Mencarelli C, Lupetti P, Rosetto M, Mercati D, Heuser JE, Dallai R. Molecular structure of dynein and motility of a giant sperm axoneme provided with only the outer dynein arm. Cell Motil Cytoskeleton. 2001;50:129-46.

53. Yanagimachi R. Mammalian fertilization. In: Knobil E, Neil JD, editors. The Physiology of Reproduction. New York: Physiol Reprod Raven Press Ltd; 1994. p. 189-317.

54. Harper CV, Cummerson JA, White MRH, Publicover SJ, Johnson PM. Dynamic resolution of acrosomal exocytosis in human sperm. J Cell Sci. 2008;121:2130-5.

55. Anderson RA, Feathergill KA, Waller DP, Zaneveld LD. SAMMA induces premature human acrosomal loss by Ca2+signaling dysregulation. J Androl. 2006;27:568-77.

56. Kaur K, Kaur S, Prabha V. Exploitation of sperm-Escherichia coli interaction at the receptor-ligand level for the development of anti-receptor antibodies as the vaginal contraceptive. Andrology. 2015;3:385-94.

\section{Publisher's Note}

Springer Nature remains neutral with regard to jurisdictional claims in published maps and institutional affiliations.

Ready to submit your research? Choose BMC and benefit from:

- fast, convenient online submission

- thorough peer review by experienced researchers in your field

- rapid publication on acceptance

- support for research data, including large and complex data types

- gold Open Access which fosters wider collaboration and increased citations

- maximum visibility for your research: over $100 \mathrm{M}$ website views per year

At BMC, research is always in progress.

Learn more biomedcentral.com/submissions 